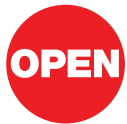

SUBJECT AREAS:

ENVIRONMENTAL

SCIENCES

AGRI-ECOLOGY

GELS AND HYDROGELS

SELF-ASSEMBLY

Received

24 October 2012

Accepted

25 January 2013

Published

18 February 2013

Correspondence and requests for materials should be addressed to S.B. (sb@orgchem.iisc. ernet.in)

* These authors contributed equally to this work.

$\uparrow$ Current address:

National Bureau of Agriculturally Important Insects, Indian Council of Agricultural Research, Bangalore 560 024, India

\section{Efficient Management of Fruit Pests by Pheromone Nanogels}

\author{
Deepa Bhagat $^{1 * \dagger}$, Suman K. Samanta ${ }^{1 *} \&$ Santanu Bhattacharya ${ }^{1,2,3}$
}

${ }^{1}$ Department of Organic Chemistry, Indian Institute of Science, Bangalore 560012, India, ${ }^{2} \mathrm{~J}$. C. Bose Fellow, Department of Science and Technology, New Delhi, ${ }^{3}$ Also at JNCASR, Bangalore 560012 , India.

Environment-friendly management of fruit flies involving pheromones is useful in reducing the undesirable pest populations responsible for decreasing the yield and the crop quality. A nanogel has been prepared from a pheromone, methyl eugenol (ME) using a low-molecular mass gelator. This was very stable at open ambient conditions and slowed down the evaporation of pheromone significantly. This enabled its easy handling and transportation without refrigeration, and reduction in the frequency of pheromone recharging in the orchard. Notably the involvement of the nano-gelled pheromone brought about an effective management of Bactrocera dorsalis, a prevalent harmful pest for a number of fruits including guava. Thus a simple, practical and low cost green chemical approach is developed that has a significant potential for crop protection, long lasting residual activity, excellent efficacy and favorable safety profiles. This makes the present invention well-suited for pest management in a variety of crops.

$\mathrm{T}$ he pest management practices throughout the world are increasingly leaning toward more environment friendly agriculture without disturbing the balance of the eco-system ${ }^{1}$. Thus, the evolution of modern organic agriculture depends on biological control agents to disrupt and control pest attacks which impart serious adverse effects on the agricultural economy ${ }^{2}$.

Guavas (Psidium guajava Linn.) comprise plants that contain nearly hundred species of tropical shrubs and trees. Guavas are rich in dietary fibers, minerals, vitamins $\mathrm{A}$ and $\mathrm{C}$ and folic $\mathrm{acid}^{3}$. The fruit is native to central and northern South America, and cultivated throughout in South-east Asia, Florida, Hawaii, the Caribbean and Africa $^{3}$. Fruitfly (Bactrocera dorsalis Hendel, Figure 1a) is considered to be a harmful key pest of guava. It causes significant yield losses and quality degradations of the fruits particularly during the rainy season ${ }^{4}$. This results in a poor commercialization of the crops in domestic markets and imposes quarantine restrictions from the international markets ${ }^{5}$. Bactrocera dorsalis (B. dorsalis) are polyphagous ${ }^{6}$ pests and it breeds on a number of other fruits and vegetables as well. For example, fruits such as, apple (Annona squamosa), banana (Musa paradisiaca), mango (Mangifera indica), orange (Citrus sinensis), peach (Prunus persica), plum (Prunus domestica) etc. are also affected by this fruit fly ${ }^{7,8}$. The fruit flies are attracted toward the concerned fruits and infect them (Figure $1 \mathrm{~b}$ ). Attacked fruits show signs of ovipositional damage in the form of minute depressions which can be even seen from outside (Figure 1c, d). The affected fruits soften at the infested positions, then disintegrate and eventually drop down prematurely (Figure 1e). Eggs of $B$. dorsalis are laid below the skin of the host fruit and the maggots feed on the pulp of the fruits (Figure 1f). These hatch within $\sim 1-3$ days and the larvae feed for another 9-35 days. The pupariation process occurs in the soil near the host plant and the adult flies emerge after $\sim 1-2$ weeks and persist throughout the year?.

For the pest management of $B$. dorsalis, several methods have been developed in the last few decades. These pest management practices include destruction of the fallen and infested fruits ${ }^{10}$, cold treatment ${ }^{11}$, heat teatment $\mathrm{t}^{12,13}$, bait sprays method containing protein hydrolysate ${ }^{14}$, biological control method ${ }^{15}$, sterile insect techniques ${ }^{16,17}$ etc. However, most of these treatments fail due to one or another type of drawbacks. Use of insecticides provides another alternative. But it affects both the agricultural fields, habitation and even the locality resulting in affecting non-target species such as humans, mammals, arthropods and other natural enemies ${ }^{18}$. In addition, the pest populations have increasingly become resistant to the chemical pesticides compelling the farmers to resort to an use of even larger amounts of pesticides ${ }^{19-21}$. These pose significant risk on the human health and the environment in a bid to achieve appropriate control of the pest.

To alleviate such problems highly viscous hydrogels have been used to deliver pheromones ${ }^{22}$. However, hydrogels often swell and shrink with the changes in humidity and temperature. Therefore, such hydrogels cannot be used in all seasons and in particular during the rainy season. Male annihilation technique has been used in the pest management of $B$. dorsalis due to the attraction of males to methyl eugenol (ME) at very low 


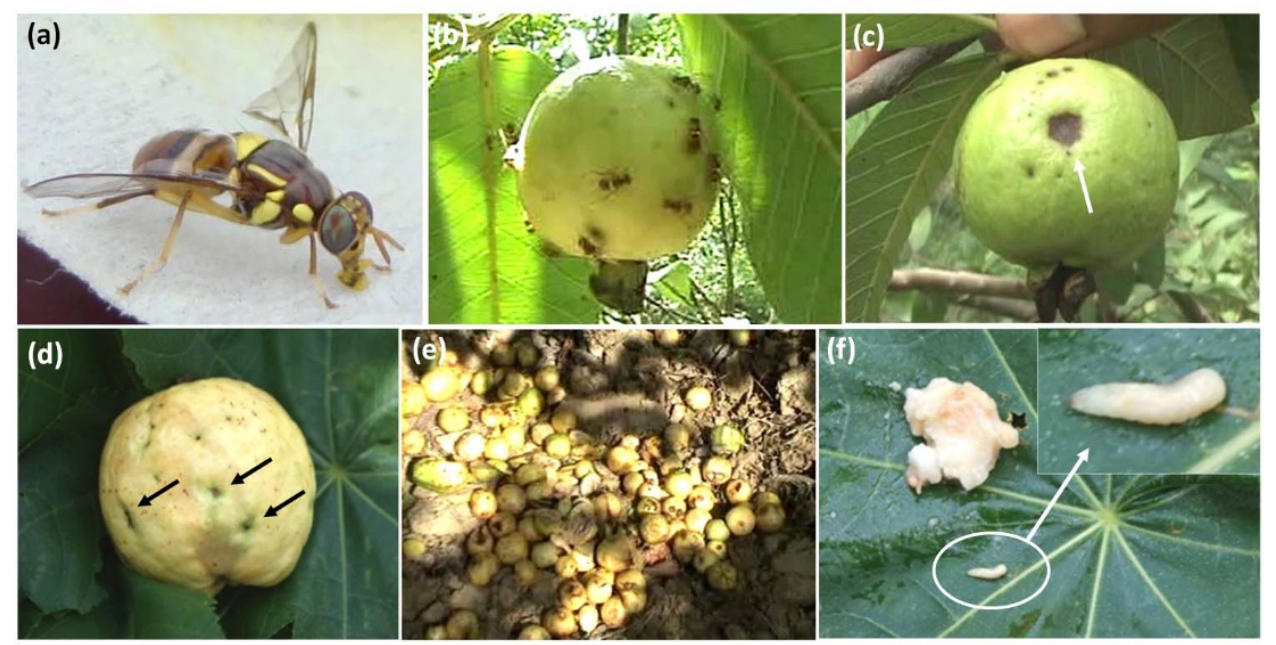

Figure $1 \mid$ (a) Photograph of an adult B. dorsalis fruit fly; (b) infection of the fruit guava by B. dorsalis; (c, d) eggs of B. dorsalis laid below the skin of the host fruit and the attacked fruit shows the signs of the ovipositional damage in the form of minute depressions; (e) the affected fruits soften at the site of infestation which then rot and drop down prematurely and (f) the maggots feed on the pulp of the fruits.

concentrations ${ }^{23,24}$. However, there is a significant limitation in that these solutions contain pesticides and have a limited shelf-life.

To overcome these problems a new yet simple approach is essential which should provide viable solutions in the pest management arena. Pheromones are naturally occurring volatile semiochemicals and are considered as eco-friendly biological control agents ${ }^{25}$. They induce impaired sexual communication and mating disruptions among pests ${ }^{26}$. High specificity of pheromones towards a given species further enables pest control without weakening the beneficial organisms ${ }^{27}$. However, due to the unstable nature of pheromones, such as photo-oxidation, auto-oxidation, isomerization and volatility etc. ${ }^{28}$, the formulation development for the field trials involving pheromones needs a major refinement specifically in terms of the slow-release and protection from decomposition under ambient conditions ${ }^{29}$. ME in this context may be useful since it belongs to the class of a para-pheromone which mimics the role of a male attractant ${ }^{30,31}$. Using supramolecular self-assembly principles and nanotechnology we have been able to achieve an increased shelf-life of the pheromone (ME) when immobilized in a nanogel. We demonstrate here that such pheromone nanogels exhibit high residual activity, excellent efficacy in open orchard even during adverse seasons and are also environment friendly.

\section{Results}

Nanotechnology plays a pivotal role in the increase of the effectiveness of pheromones in terms of their increased shelf-life through their entrapment by suitable host matrix ${ }^{32}$. Low-molecular mass gelators (LMMGs) have attracted much attention because of their interesting properties and potential uses in various fields of research and industry ${ }^{33,34}$. LMMGs such as all-trans tri( $p$-phenylenevinylene) bis-aldoxime $(1)^{35}$, self-assemble through weak intermolecular noncovalent interactions such as hydrogen bonding, $\pi-\pi$ stacking and van der Waals leading to the gelation of specific solvents (Figure 2$)^{36-39}$. In the present work, we demonstrate the nanogel formation upon entrapment and immobilization of ME into the entangled threedimensional nano-sized supramolecular networks of 1 . Such nanogels provide high pheromone retention capacity, enhanced shelf-life and protection of ME from environmental decompositions (from exposure to ambient air, water and sunshine). ME alone however, is quite volatile on its own and evaporates under ambient conditions significantly rapidly during the summer (see below).

Immobilization of methyl eugenol in nanogels. The present invention describes a simple and practical method by which pheromones could be immobilized in the nanogels. ME alone is a colorless semi-viscous liquid (Figure 2b) which turns yellow (Figure $2 \mathrm{c})$ on solubilization of the gelator $1(2.5 \mathrm{mg} / \mathrm{mL})$ upon brief warming of the mixture to $\sim 65^{\circ} \mathrm{C}$. In this condition, the pheromone did not undergo any decomposition. When cooled to room temperature without any external perturbation for a period of 10-15 min, the yellow solution turned into a thick, viscous orange colored mass, which did not flow under the influence of gravity when the vial was inverted upside down demonstrating the onset of gelation (Figure 2d). The gelation was retained unperturbed even after several consecutive heating and cooling cycles (from room temperature to $70^{\circ} \mathrm{C}$ ). The nanogel was thermoreversible in nature, a property which was found to be useful for its long term use in the field. Thus the preparation of the nanogels $(1+\mathrm{ME})$ is indeed convenient without requiring addition of any organic solvents or chemical cross-linking agents etc. Also, after several heat-cool cycles, or upon exposure to open orchard for a number of weeks, neither a thermal or photo-chemical decomposition of ME occurred as evidenced from GC-MS analysis (see, Supplementary Information, [SI] Figure S1 and S2). This ensured good chemical stability of the resulting nanogels.

The minimum amount of the gelator (1) required for the formation of the gel is known as the minimum gelator concentration (MGC). This was estimated to be $\sim 2.5 \mathrm{mg} / \mathrm{mL}$ indicating high ME content in the nanogel. Thus as little as $\sim 2.5 \mathrm{mg}$ of 1 could immobilize about $1 \mathrm{~mL}$ of ME. The freeze-dried gel was further characterized using both transmission electron microscopy (TEM) and scanning electron microscopy (SEM). The presence of three-dimensional nano-sized fibrillar networks having fiber diameters ranging from 100-200 nm was evidenced. These fibers collate upon themselves in the nanogel to form aggregated bundles having the fiber diameters ranging from $500 \mathrm{~nm}$ to $1 \mu \mathrm{m}$ (Figure 3).

Thermal stability of nanogels. The melting temperature of the nanogels, i.e. gel-to-sol transition $\left(T_{\text {gel }}\right)$ increased progressively with increasing concentration of 1 , a phenomenon that is general for many LMMGs (Figure 4a) ${ }^{34,35}$. This indicates that, with increasing concentration of the gelator, the density of the gel assembly increases ensuring participation of a larger number of gelator molecules per unit volume in the thermally induced transitions. At the concentration of $12 \mathrm{mg} / \mathrm{mL}$ of 1 in $\mathrm{ME}$ the $T_{\text {gel }}$ reached $\sim 63^{\circ} \mathrm{C}$ which was well above the ambient temperature even during peak summer in India. Thus the thermal stability of the sample should 

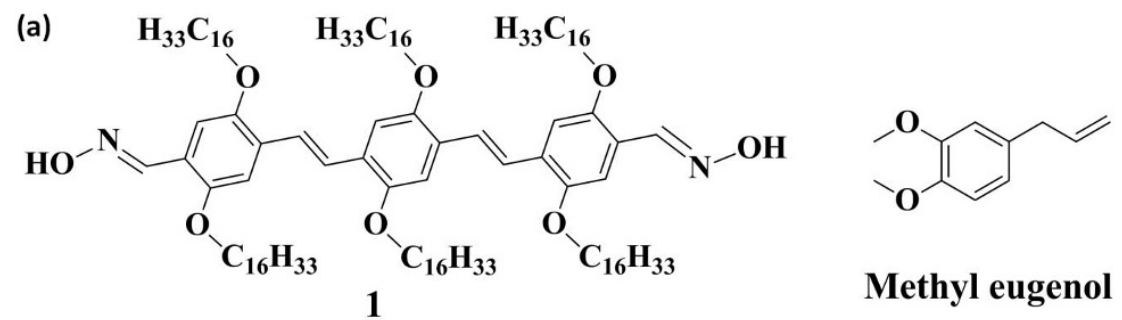

\section{Methyl eugenol}
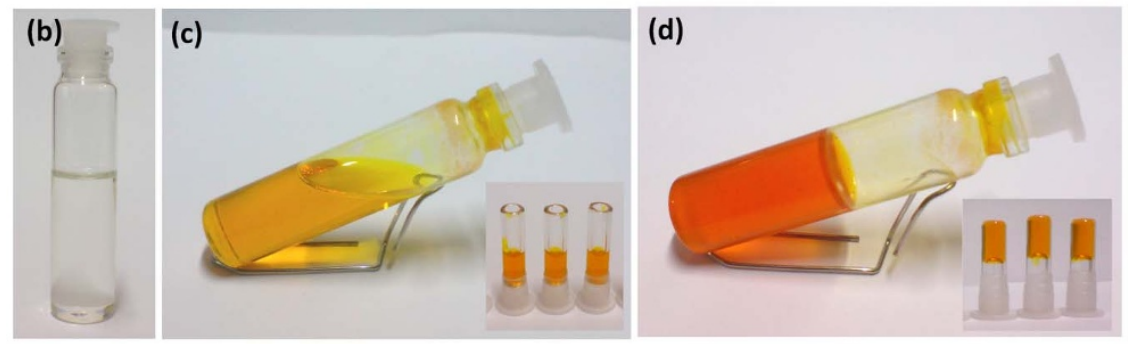

Figure $2 \mid$ (a) Molecular structures of the gelator, 1 and methyl eugenol (ME). Photographs showing (b) colorless ME, (c) a 'sol' after warming $12 \mathrm{mg} / \mathrm{mL}$ of 1 in $\mathrm{ME}$ at $70^{\circ} \mathrm{C}$; inset shows glass vials holding $0.2 \mathrm{~mL}$ of the 'sol' and (d) a 'gel' at room temperature $\left(25^{\circ} \mathrm{C}\right)$ after cooling the previous solution without any external perturbation; inset shows the inverted vials holding the gel suitable for the field study.

be adequate for the agricultural field trials even in hot climates around different geographical regions of the world.

Rheological properties and mechanical stability of gels. The oscillatory frequency response of the nanogel revealed that the elastic modulus $G^{\prime}$ is independent of frequency and much higher than the viscous modulus $\mathrm{G}^{\prime \prime}$ over the entire angular frequency range $(0.1-$ $100 \mathrm{rad} / \mathrm{s}$ ) at $0.01 \%$ strain amplitude (Figure $4 \mathrm{~b}$ ). A $\sim 13$-fold higher $\mathrm{G}^{\prime}$ over $\mathrm{G}^{\prime \prime}$ suggested a substantial elastic response of the gels that did not relax over the long timescale. This is a typical characteristic of the nanogels ${ }^{34,35}$. The viscoelastic solid-like nature of the gel increases with increasing concentration of 1 and it becomes sufficiently strong $\left(G^{\prime}\right.$ $\sim 2800 \mathrm{~Pa}$ ) at $12 \mathrm{mg} / \mathrm{mL}$. Under oscillatory stress, the nanogels show $\mathrm{G}^{\prime}>\mathrm{G}^{\prime \prime}$ by an order of magnitude indicating the dominant elastic behavior (stiffness) of the system and show the resistance of the mass to flow under applied stress (Figure 4c). An applied stress above which the gel starts to flow is called the yield stress $\left(\sigma_{\mathrm{y}}\right)$ and its value ( $20 \mathrm{~Pa}$ at $12 \mathrm{mg} / \mathrm{mL}$ ) is sufficiently high to provide adequate mechanical stability to prohibit the samples being relaxed (dropped) during its transportation or shipment.

Slow release of ME from the nanogels. The release pattern of the volatile pheromone in terms of its relative rates of evaporation at a particular temperature was determined both for the liquid ME alone and ME immobilized in nanogel $(12 \mathrm{mg} / \mathrm{mL})$ under identical conditions. The extent of evaporation was investigated by monitoring the weight loss from both the samples kept at four different temperatures $\left(10,20,30\right.$ and $\left.50^{\circ} \mathrm{C}\right)$ in a temperature gradient chamber. Plots of \%-weight losses vs. the number of weeks showed that the rates of evaporation were always greater from the ME alone compared to the ME immobilized in nanogel (Figure 5). The calculated slopes from the linear fit of the data at various temperatures showed that the evaporation rate of $\mathrm{ME}$ increased significantly with increasing temperatures (Figure 5e). $\mathrm{ME}$ in nanogel afforded only $\sim 2-3 \%$ weight loss after 10 weeks at $30^{\circ} \mathrm{C}$ (Figure 5) although it showed $\sim 50 \%$ weight loss at $50^{\circ} \mathrm{C}$ indicating that the weight loss occurred $\sim 13$ times slower at $30^{\circ} \mathrm{C}$ compared to that at $50^{\circ} \mathrm{C}$. On the other hand, at $\sim 50^{\circ} \mathrm{C}$ (a temperature at the peak summer in Indian subcontinents), $\mathrm{ME}$ alone evaporated entirely within 3 weeks and in contrast it took $\sim 30$ weeks for the near complete evaporation of ME from the nanogel. The extrapolated graphs for the nanogel in their weight loss profiles further indicate that, it would take $\sim 7.8$ years at $30^{\circ} \mathrm{C}$ and 12.4 years at $20^{\circ} \mathrm{C}$ for the complete evaporation of $\mathrm{ME}$ from the nanogel (SI, Figure S3). Thus, the sustainable nature of the pheromone in the nanogel for a significant period of time makes the nanogel particularly useful for the agricultural pest management applications.
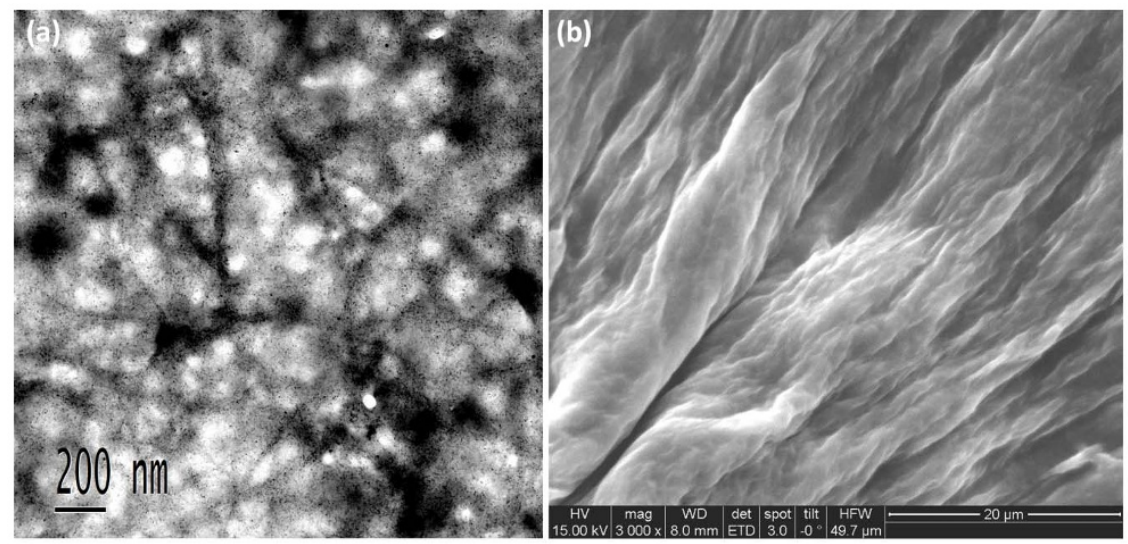

Figure $3 \mid$ (a) TEM and (b) SEM images of the nanogel showing the existence of nano-fibrillar networks. 
(a)

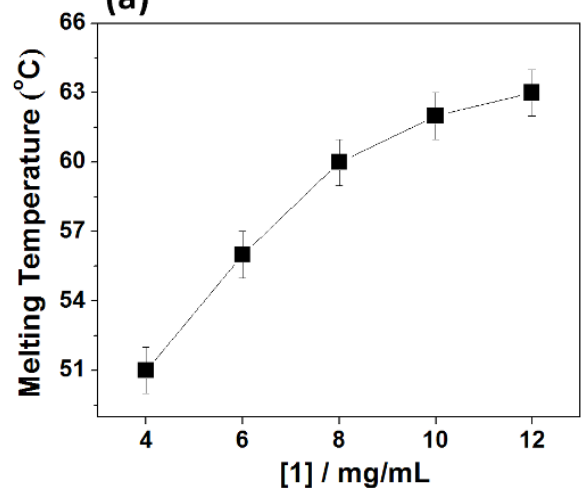

(b)

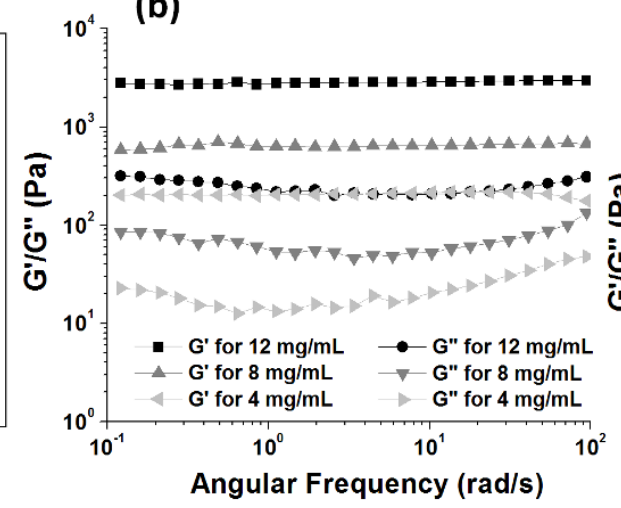

(c)

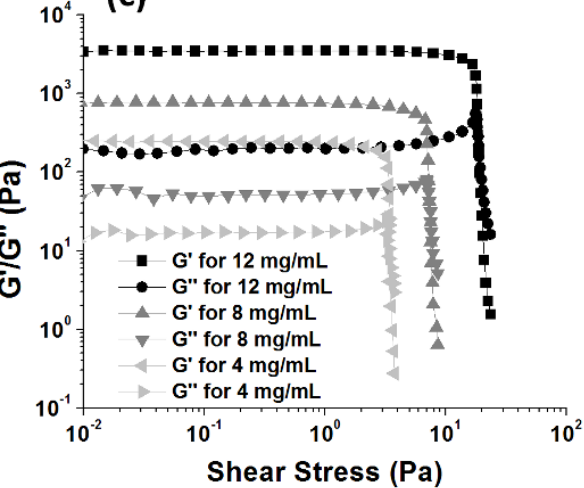

Figure $4 \mid$ (a) Plot of gel-to-sol melting temperatures as a function of the concentration of 1 indicating an improved thermal stability of the nanogels with increasing amount of 1. (b) Rheological studies of the nanogels show oscillatory frequency sweep and (c) stress amplitude sweep dependencies. With increasing amount of $\mathbf{1}$, the viscoelasticity of the gel increased providing greater mechanical stability.

Thus, the nanogel was found to be chemically, thermally and mechanically stable. The self-assembly of individual gelators is stabilized by hydrogen bonding donor $(-\mathrm{OH})$ and acceptor $(=\mathrm{N}-)$ sites, van der Waals interactions through the long aliphatic hydrocarbon chains and $\pi-\pi$ stacking through the extended aromatic $\pi$-conjugated backbones of the gelator $\mathbf{1}^{35}$. The pheromone molecules immobilized in the nanofiber networks were found to be particularly resistant to evaporation at room temperature which confirms its increased shelf-life under these conditions.

Evidence of enhanced shelf-life of ME in the nanogel. As the weight loss experiments indicated a significantly reduced evaporation rate of ME from the nanogels compared to the ME alone, a thin film of the prepared ME nanogel was cast (plate 'A', Figure 6) on glass plates to study the extent of shelf-life of the pheromone. Control experiments were performed with the cast film of 1 solubilized in toluene (plate 'B') and ME alone (plate 'C'). All the three plates were exposed to a guava orchard for a number of hours. The results showed that the fruit flies were attracted specifically to the plate $\mathrm{A}$ and to the plate $\mathrm{C}$ throughout the period and not to the plate B which held the gelator 1 in toluene (a non-pheromone solvent, see Movie S1). This indicates that the pheromone is biologically active in the nanogel and is responsible for attracting the pest although the compound 1 itself is inactive toward the fruit flies. The accumulation of the pests increased with time around both the plates $\mathrm{A}$ and $\mathrm{C}$. The same plates were preserved at room temperature $\left(\sim 30^{\circ} \mathrm{C}\right)$ and were
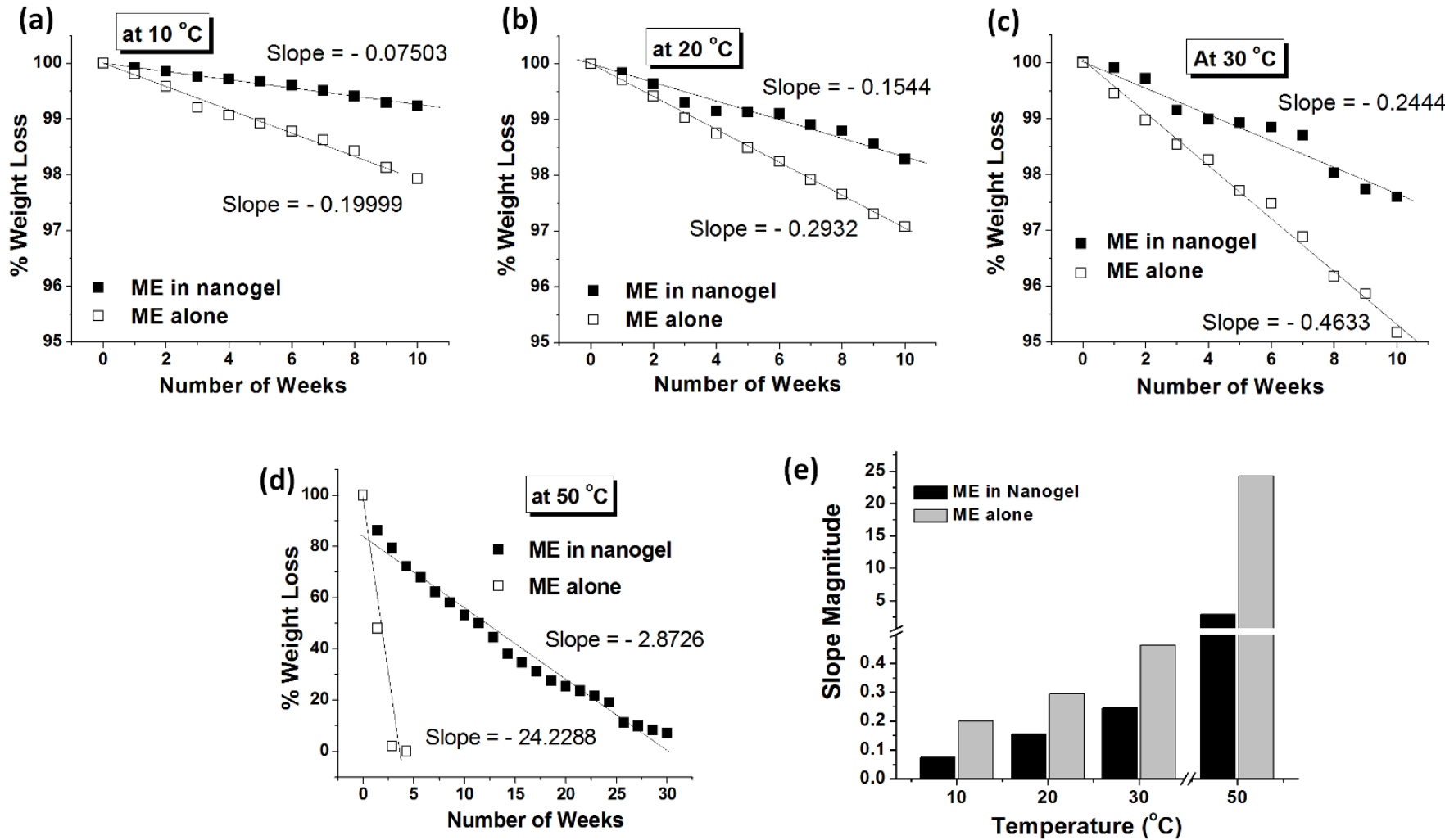

Figure $5 \mid$ Plots of percent weight losses as a function of time confirm sustained 'release' pattern of the nano-gelled pheromone (ME) studied at (a) $10^{\circ} \mathrm{C}$, (b) $20^{\circ} \mathrm{C}$, (c) $30^{\circ} \mathrm{C}$ and (d) $50^{\circ} \mathrm{C}$. (e) Histograms show a comparison of the slopes of the release patterns between ME in nanogel and ME alone.

The individual weight loss at any week is an average of three replications performed in identical conditions. 


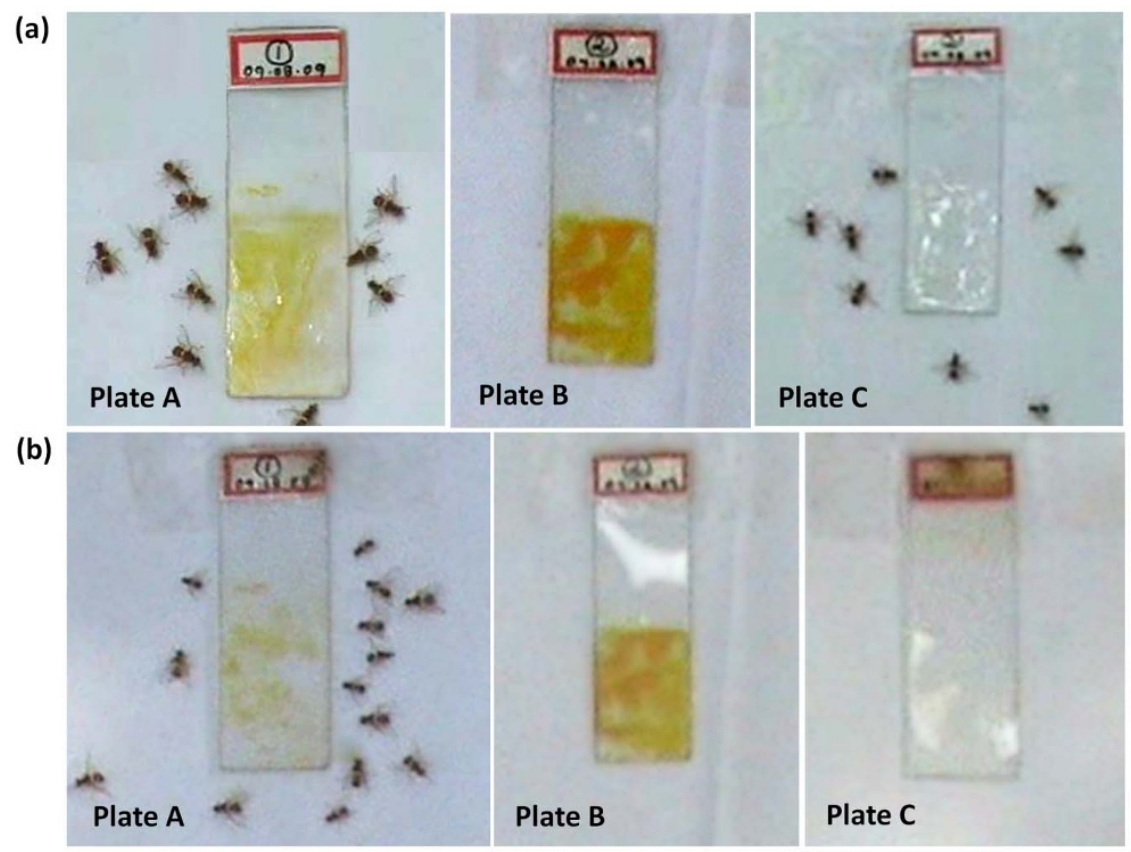

Figure 6 | (a) Thin films prepared on $09^{\text {th }}$ Aug'2009; plate A: $1+$ ME gel, plate B: gels of 1 in toluene, plate C: ME alone and the plates were exposed to a guava orchard. (b) The same plates were exposed to the guava orchard after three weeks on $31^{\text {st }}$ Aug'09.

exposed again in the same guava orchard after 21 days. Interestingly this time the fruit flies were attracted to the plate A only which contained the nanogel and not to the plate $\mathrm{B}$ or $\mathrm{C}$ for the entire time period of observation. This indicates that the nanogel laced with ME still retained the pheromone for sustained release and has also retained significant pest attractant property due to the higher shelf-life of ME in nanogel than the pure ME alone which evaporates away lot faster. This experiment also revealed that the fruit flies upon being attracted by ME released from the nanogels, gathered in the vicinity or on top of the plate. However, they did not die during this experiment (see Movie S1). This indicates that the nanogel $(1+\mathrm{ME})$ is non-toxic in nature and thus acts only as an attractant source for the fruit flies alone.

Field trials with the nanogels. The nanogel containing ME was then utilized for the efficient pest management of $B$. dorsalis as a bait trap along with a technique to kill the pest. The total area where the experiments conducted was 67274 sq. $\mathrm{ft}$. (0.625 hectare) with the distance of $15 \mathrm{ft}$. in between two adjacent trees. The samples containing ME alone and ME in nanogel were applied in the guava orchard each with six replications in such a way that the horizontal and vertical distance between the two traps was $60 \mathrm{ft}$. and $75 \mathrm{ft}$. respectively as depicted in Figure S4 (SI). The experiment was set up during the ripening stage of guava ( $9^{\text {th }}$ August, 2009) when the environmental temperature varied within $\sim 35-40^{\circ} \mathrm{C}$ and this continued till the crops were harvested ( $7^{\text {th }}$ September, 2009). The nanogels $(12 \mathrm{mg} / \mathrm{mL})$ were taken in glass vials $(5 \mathrm{~mm}$ innerdiameter, inset of Figure 2d) and placed inside plastic bottles (Figure $7 \mathrm{a}, \mathrm{b}$ ). Two holes were made in the bottles and were filled with water upto the white arrow level as shown in Figure $7 \mathrm{~b}$ (also c.f. Methods for the detailed Sampling Process). Control experiments were also performed with ME by directly adding it into water in the plastic bottles as convenient to the previously existing method $^{40}$. Due to the presence of pheromone, the pests were attracted towards the hanging vials containing the nanogel only. During this event a significant number of fruit flies fell into water, which followed by their drowning and eventual death. Dead pests were finally collected by filtration and the total number of killed flies were counted (Figure $7 c, d$ ) and summarized against events recorded each day in Table S1 (see SI). The number of trap catches for the control containing only ME was significantly lower in comparison to the nanogel throughout the experiment.

The number of catches for the control bottle containing ME alone also attracted pests initially. However, this showed a progressive decrease in comparison to the bottle containing nanogel and from the $8^{\text {th }}$ day onward no fly was attracted to this bottle. This indicates that the effectiveness of ME alone towards the $B$. dorsalis without the gelator 1 is at best limited to one week in the real field environment (Figure 7e). On the contrary significant counts of $B$. dorsalis catches were continually recorded almost throughout the month with peak trap catches occurring during the first three weeks as compared to the control. After harvesting all the guavas, the infestation of $B$. dorsalis was found to be remarkably lower as shown in the results after three weeks of experiment since the number of catches got reduced. However, the nanogels were still active in releasing pheromone as revealed from the weight loss experiments which were conducted upto ten weeks. The procedure is therefore reproducible and particularly attractive due to the low cost, simplicity, selectivity and efficiency of the sampling technique. This also produced high yield and damage free crops.

Statistical Analysis of Variance (ANOVA) were performed on the collected data containing the number of trap catches in each day throughout the experiment (30 days) for all the replications (6 for both ME alone and ME in nanogel) of the pheromone containing samples (Table S1, SI). The two-factor ANOVA calculations considering the factor 1 as treatment (number of trap catches) and factor 2 as the period of observations (days), were carried out on the transformed data $\left[(\mathrm{x}+0.5)^{1 / 2}, \mathrm{x}=\right.$ number of trap catches in each day $]$ to homogenize the variances (Table S2, SI) ${ }^{41}$. The interaction between the treatments $(t)$ and the period of observations (d) has been calculated from the data presented in Table 1 to obtain the extent of significance of the experiments.

The two-factor ANOVA calculations showed that the computed $\mathrm{F}$ value was larger than the tabular $\mathrm{F}$ value both at probability $(p)<$ 0.05 and $p<0.01$ level of significance for the treatments $(\mathrm{t})$, period of observations (d) as well as the interaction between the two $(t \times d)$ (Table 2). This suggests that the difference between the treatments, the period of observations pertaining to fruit flies' visitation and the 

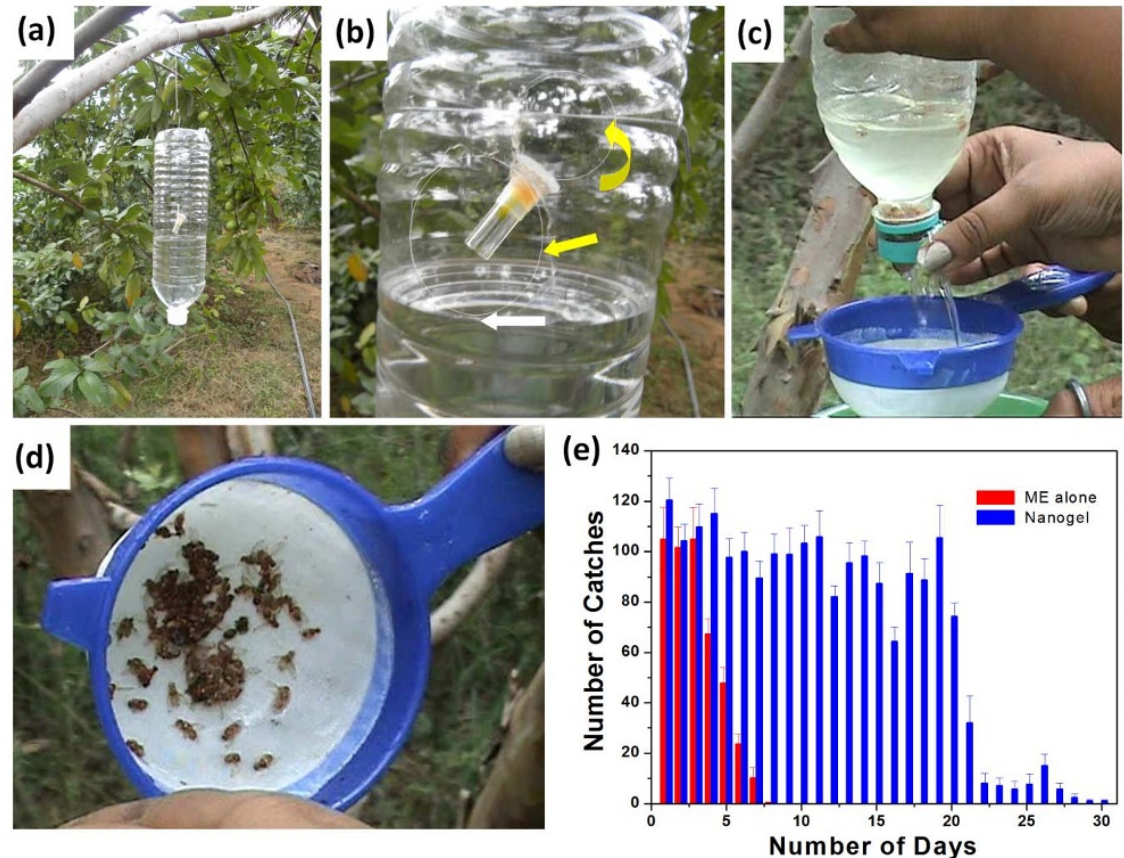

Figure $7 \mid$ (a) A simple and low cost sampling technique in which nanogels are placed just above the water level contained inside plastic bottles.

This arrangement was distributed throughout the guava orchard. (b) A view of the sampling process where in the plastic bottle, two holes were made oppositely up (rear-side shown by yellow rear-arrow) and down (front-side yellow arrow) to each other and filled with water near the level of the down hole (shown by white arrow). The nanogel was placed inside the bottles just above the water level. Control experiments were performed with ME added directly into the water $\sim 2 \mathrm{~cm}$ below the level of the down hole. (c) Owing to the presence of pheromone, the fruit flies were attracted towards the bottles and fell down into the water and drowned to eventual death. (d) Dead flies were filtered and their numbers were counted. (e) Plot represents averages $( \pm \mathrm{SE}, \mathrm{n}=6)$ of the number of dead flies for the nanogel and the control (ME alone).

interaction between the treatments ( $\mathrm{t} 1$ and $\mathrm{t} 2$ ) with the period of observations is highly significant. The coefficient of variation $(\mathrm{CV})$ is $19.39 \%(<20 \%)$ (Table 2) indicating that the degree of precision with which the treatments were compared, showed a good index of reliability of the experiments ${ }^{42}$.

The least significant difference (LSD) calculated (with AgRes software) for the treatments (ME alone and ME in nanogel), the period of observations (days) and the interaction between the two $(t \times d)$ considering the mean values are all presented in the Table 1. LSD results clearly indicate that the treatment 2 ( $\mathrm{t} 2, \mathrm{ME}$ in nanogel) is more efficient than the treatment 1 ( $\mathrm{t} 1, \mathrm{ME}$ alone) in trapping fruit flies (see AgRes results in Table S5, Supplementary Information) as the critical difference (CD) between the treatments is 0.193 ( $p<$ 0.05). This further indicates that there is significant difference between the mean for the treatment $1(2.32)$ and treatment 2 (7.34). The differences between the mean values of the periods of observations (days) were estimated using LSD considering the CD = $0.749(p<0.05)$ which showed a descending order of distribution among days (Table S3, SI). The maximum number of fruit flies catches was recorded on the first three days. As the days progressed

\begin{tabular}{|c|c|c|c|c|c|c|c|}
\hline 1 & 105 (10.18) & $120.5(10.95)$ & 112.75 (10.57) & 16 & $0(0.71)$ & 64.33 (8.01) & $32.17(4.36)$ \\
\hline 3 & 105 (10.18) & $109.83(10.46)$ & $107.42(10.32)$ & 18 & $0(0.71)$ & $88.83(9.4)$ & 44.42 (5.05) \\
\hline 4 & 67.33 (8.19) & 115 (10.69) & $91.17(9.44)$ & 19 & $0(0.71)$ & 105.5 (10.19) & $52.75(5.45)$ \\
\hline 5 & $47.83(6.87)$ & $97.66(9.87)$ & 72.75 (8.37) & 20 & $0(0.71)$ & 74.33 (8.62) & $37.17(4.66)$ \\
\hline 8 & $0.33(0.85)$ & $99.16(9.94)$ & 49.75 (5.39) & 23 & $0(0.71)$ & $7.17(2.43)$ & $3.58(1.57)$ \\
\hline 9 & $0(0.71)$ & $98.83(9.89)$ & $49.42(5.3)$ & 24 & $0(0.71)$ & $5.83(2.16)$ & $2.92(1.43)$ \\
\hline 10 & $0(0.71)$ & $103.33(10.15)$ & $51.67(5.43)$ & 25 & $0(0.71)$ & $7.66(2.34)$ & $3.83(1.52)$ \\
\hline 11 & $0(0.71)$ & $105.83(10.24)$ & $52.92(5.47)$ & 26 & $0(0.71)$ & $15.16(3.69)$ & $7.58(2.20)$ \\
\hline 12 & $0(0.71)$ & $82.16(9.07)$ & 41.08 (4.89) & 27 & $0(0.71)$ & $5.83(2.21)$ & $2.92(1.46)$ \\
\hline 13 & $0(0.71)$ & 95.5 (9.75) & 47.75 (5.23) & 28 & $0(0.71)$ & $2.5(1.54)$ & $1.25(1.12)$ \\
\hline Critic & ence between the & teractions $(t \times d)$ & & & $1.059 *$ & & \\
\hline
\end{tabular}


Table 2 | Two-factor ANOVA calculations of the transformed data of guava field trials

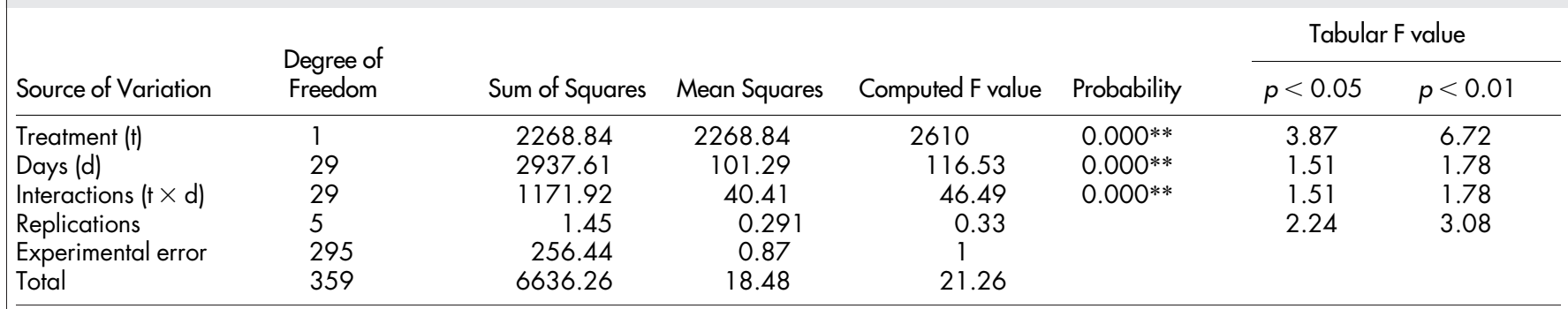

${ }^{*+}$ Significant at $p<0.05$ and $p<0.01$; Coefficient of variation $(C V)=19.39 \%\left[(C V)=\left\{(\text { Error Mean square })^{1 / 2} /\right.\right.$ Grand Mean $\left.\} \times 100\right]$

and guava fruits were harvested fruit flies infestation in field became gradually less significant and thus the lowest number of trap catches took place from the day 23 to day 30 . LSD calculations were also performed from the mean values for the comparison of the interactions between the treatments and the period of observations $(t \times d)$ considering $\mathrm{CD}=1.059(p<0.05)$ and the relevant data are recorded in Table S4 (SI). Treatment 1 (ME alone) and treatment 2 (ME in nanogel) were at par on the first three days and from day 8 , the treatment 2 showed more effectiveness than the treatment 1 (Table S4, Group o). Therefore, ME immobilized in nanogel acted as an effective formulation compared to $\mathrm{ME}$ alone for the pest management of $B$. dorsalis in the field trial studies.

\section{Discussion}

The present invention provides a simple and effective route to a slow delivery of pheromones from a nanogel. This does not require any use of environmentally harmful and toxic chemicals such as, crosslinkers, antioxidants, antimicrobials, pesticides, volatile organics etc. While other existing methods pose risk of human contacts where ME is added to water in the bait, the present method avoids any direct contact with the fruit crop and the agricultural workers with pheromone. This keeps the crop absolutely clean from the chemical contaminations unlike the prevalent practice of spraying toxic pesticides on the orchard. Moreover, the aggressive techniques like destruction of fallen and infested fruits, cold or vapor-heat treatments, hot-water treatment, forced hot-air treatment etc. are avoided in the present approach which makes this economically viable as well.

The nanogel of pheromone ME described herein is insoluble in water, which makes it superior to hydrogels and microcapsules. The nanogel does not significantly swell and shrink in presence of water, confirming that the humidity plays no effect whatsoever on this material. This pheromone nanogel is particularly useful for the pest management even in rainy season as $B$. dorsalis shows maximum activity during the rainy season resulting in the most significant yield loss of crops. It may be further noted that, use of microcapsules encounters problems associated with capsule bursts or potential leaks. These critical drawbacks have been avoided in the present method.

The flexibility in using the nanogel in any season at any temperature $\left(<60^{\circ} \mathrm{C}\right)$ are feasible due to the oxidative, photochemical and thermal stability of the nanogel. Also the transportation of the nanogel based samples is trouble free due to their significant mechanical strength. This is a very general method and the present finding could be potentially useful in preparing new nanogel type formulations with other pests such as Helicoverpa armigera (Hubner) (Lepidoptera, Noctuidae), Scirphophaga incertulas (Walker) (Lepidoptera, Pyralidae), Leucinodes orbonalis (Guenee) (Lepidoptera: Pyralidae) etc. with suitable LMMGs and appropriate pheromones that attract these species. This strategy may also be applicable even for kairomones for the attraction of predators and parasitoids (natural enemies). Such an approach could therefore be efficiently carried forward from the laboratory to the agricultural field.
In summary, this is a simple and straightforward method where a nanogel is prepared as a controlled release system to deliver fruit fly pheromone that remains active over a sustained period in an environmentally safe manner. In view of the demonstrated efficiency of this pheromone nanogel in a fruit orchard, in rainy season and also in humid, sunny peak summer months, this approach should be useful in pest control in most parts of the world.

\section{Methods}

Materials. Commercial ME was obtained from Sisco Research Laboratories Pvt. Ltd., India and was used without further purification. Gelator 1 has been synthesized as reported earlier ${ }^{35}$.

Scanning electron microscopy (SEM). The nanogels were carefully scooped onto the brass stubs and were freeze-dried. The samples were then coated with gold vapour and analyzed on a Quanta 200 SEM operated at $15 \mathrm{kV}$.

Transmission electron microscopy (TEM). A solution of $1+\mathrm{ME}\left(1 \times 10^{-4} \mathrm{M}\right)$ was loaded onto a carbon coated copper grid (200 mesh size) and the TEM images were recorded on a TECNAI F30 instrument.

GC-MS studies. Samples were analyzed on a gas-chromatograph (GC 17A, Shimadzu) coupled with a mass-spectrometer (GC-MS QP 5050 Shimadzu) with an electron impact ionization at $70 \mathrm{eV}$. The GC was equipped with a WCOT fused silica stationary phase CP-Sil 5CB open tubular capillary column DB-5 ms (30 m $\times$ $0.25 \mathrm{~mm}$, I.D. $0.25 \mu \mathrm{M}$ ) using helium as carrier gas (flow rate $1.3 \mathrm{ml} / \mathrm{min}$ ). The temperature was programmed from $60^{\circ} \mathrm{C}$ (hold $5 \mathrm{~min}$ ) to $250^{\circ} \mathrm{C}$ at $10^{\circ} \mathrm{C} / \mathrm{min}$. The samples were introduced at the injector temperature of $250^{\circ} \mathrm{C}$. Tentative identification of each compound was achieved based on the comparison of matching of the respective mass spectrum as recorded in the Wiley 139 computer databases. Identification of ME was ensured from a comparison with the mass spectra and the GC retention data with those of the known standards.

Determination of gel melting temperatures $\left(T_{\text {gel }}\right)$. The melting temperature of the nanogels from gel-to-sol was determined by an 'inverted vial' method. A sealed glass vial containing $0.5 \mathrm{~mL}$ of nanogel was gradually heated $\left(2^{\circ} \mathrm{C} / \mathrm{min}\right)$, and the temperature at which the gel started to flow under gravity was recorded as the gel melting temperature. Each experiment was performed in duplicate to determine the reproducibility.

Weight loss studies. Mini glass containers of fixed $(5 \mathrm{~mm})$ diameter containing $0.2 \mathrm{~mL}$ of nanogel samples (in three replications for each sample) were placed inside a temperature gradient chamber (NK system, model: TG-180 CCFL-5LE) and were allowed to evaporate slowly. The weights were recorded on a weekly basis.

Rheological studies. An Anton Paar 100 rheometer using a cone and plate geometry (CP 25-2) with a gap distance fixed at $0.05 \mathrm{~mm}$ was utilized. The rheometer has a built-in computer which converts the torque measurements into either $\mathrm{G}^{\prime}$ (the storage modulus) and $\mathrm{G}^{\prime \prime}$ (the loss modulus) in oscillatory shear experiments. The nanogel was first scooped on the plate of the rheometer and then a stress amplitude sweep experiment was performed at a constant oscillation frequency of $1 \mathrm{~Hz}$ for the strain range of 0.01 to $500 \%$ at $20^{\circ} \mathrm{C}$. Oscillatory frequency sweep experiments were performed in the linear viscoelastic region $(0.01 \%$ stain amplitude) by varying the angular frequency range $(0.1-100 \mathrm{rad} / \mathrm{s})$ to ensure that the calculated parameters correspond to an intact network structure.

Sampling process. We have taken a $\sim 25 \mathrm{~cm}$ long plastic bottle of $\sim 7 \mathrm{~cm}$ diameter with a closed screw-cap. This is kept hanging from the branch of a tree with the help of a hook in an upside down orientation. Two circular holes (diam. $\sim 4.5 \mathrm{~cm}$ ) have been made on the bottle in such a way that they face up and down opposite to each other. Two holes are useful for the facile passage of fruit flies that are attracted to pheromone. Water is introduced into the bottle through the lower hole and 
maintained at nearly the same level. The pheromone nanogel sample is kept in a hanging vial and its opening faces downwards just a few $\mathrm{cm}$ above the water level. With this arrangement, even when it rains, the excess of water gets automatically drained away from the lower hole allowing it to maintain the water level. As the opening of the nanogel vial is oriented downwards, rain water cannot enter into it Also at the end of each day, the contents from the plastic bottle may be released by opening the screw-cap. This allows collection of dead flies after the day-long exposure in the orchard. The same bottle may be reused following the above procedure throughout the season.

Field studies. The experiment was conducted at Amrud Odyan Ropan under Rastriya Audhanik Mission at Gosaipur Mohab, Varanasi, Uttar Pradesh, India. Total area of the orchard was 0.625 hectare ( 67274 sq. $\mathrm{ft}$ ) with the distance of 15 feet in between two adjacent trees. The experiment was conducted during rainy season for a period of 30 days from $9^{\text {th }}$ August to $7^{\text {th }}$ September, 2009. We took 6 replications for each sample containing $\mathrm{ME}$ in nanogel and $\mathrm{ME}$ alone. Dead pests were counted everyday for each bottle and were averaged from six bottles under each category. Thus the data containing ME samples represents a randomized block design (RBD model) ${ }^{42}$.

Statistical analysis. The data were analyzed with the AgRes software (version 7.01) ANOVA (Analysis of Variance) Package for Researchers 1994, Pascal Intl software solutions. The data entry was executed using AGDATA AgRes (version 3.01) in the data entry module for the AgRes Statistical Software 1994 (Pascal Intl software solutions). Significance is assessed at 95\% $(\mathrm{p}<0.05)$ and $99 \%(\mathrm{p}<0.01)$ level of confidence. F values were calculated using the method as described in http:// www.biokin.com/tools/fcrit.html.

1. Tilman, D., Cassman, K. G., Matson, P. A., Naylor, R. \& Polasky, S. Agricultural sustainability and intensive production practices. Nature 418, 671-677 (2002).

2. Copping, L. G. \& Menn, J. J. Biopesticides: a review of their action, applications and efficacy. Pest Manage. Sci. 56, 651-676 (2000).

3. Nutrition data, know what you eat; guavas, common, raw. http:// nutritiondata.self.com/facts/fruits-and-fruit-juices/1927/2 (retrieved on $11^{\text {th }}$ April, 2012).

4. Allwood, A. J. et al. Host plants for fruit flies (Diptera; Tephritidae) in South East Asia. Raff. Bull. Zoology, Supplement 1-92 (1999)

5. Vayssieres, J.-F., Wharton, R., Adandonon, A. \& Sinzogan, A. Preliminary inventory of parasitoids associated with fruit flies in mangoes, guavas, cashew pepper and wild fruit crops in Benin. BioControl 56, 35-43 (2011).

6. Shelly, T. et al. Capture probability of released males of two Bactrocera species (Diptera: Tephritidae) in detection traps in California. J. Econ. Entomol. 103, 2042-2051 (2010).

7. Koyama, J. Pest status; south-east Asia and Japan. In: World Crop Pests 3(A). Fruit flies; their biology, natural enemies and control, 63-66 (1989).

8. Iwaizumi, R. Species and host record of the Bactrocera dorsalis complex (Diptera: Tephritidae) detected by the plant quarantine of Japan. Appl. Entomol. Zool. 39, 327-333 (2004).

9. Christenson, L. D. \& Foote, R. H. Biology of fruit flies. Ann. Rev. Entomol. 5 171-192 (1960).

10. Liquido, N. J. Reduction of oriental fruit fly populations in papaya orchards by field sanitation. J. Agr. Entomol. 10, 163-170 (1993).

11. Burikam, I., Sarnthoy, P., Charensom, K., Kanno, T. \& Homma, H. Cold temperature treatment for mangosteens infested with the oriental fruit fly. J. Econ. Entomol. 85, 2298-2301 (1992)

12. USDA Treatment manual. USDA/APHIS, Frederick, USA (1994)

13. Armstrong, J. W., Hu, B. K. S. \& Brown, S. A. Single-temperature forced hot-air quarantine treatment to control fruit flies (Diptera: Tephritidae) in papaya. J. Econ. Entomol. 88, 678-682 (1995).

14. Roessler, Y. Insecticidal bait and cover sprays. In: World Crop Pests $3 A \& B$. Fruit flies: their biology, natural enemies and control. 337-345 (1989).

15. Wharton, R. H. Control; classical biological control of fruit-infesting Tephritidae. In: World Crop Pests 3B. Fruit flies; their biology, natural enemies and control. 303-313 (1989).

16. Dyck, V. A. et al. Sterile insect technique: principles and practice in area-wide integrated pest management. Springer, Dordrecht, 525-545 (2005).

17. Shelly, T. E., Edu, J. \& McInnis, D. Pre-Release consumption of methyl eugenol increases the mating competitiveness of sterile males of the oriental fruit fly, Bactrocera dorsalis, in large field enclosures. J. Insect. Sci. 10, 1-16 (2010).

18. Leroy, P. D. et al. Microorganisms from aphid honeydew attract and enhance the efficacy of natural enemies. Nat. Commum. 2, 348-354 (2011).

19. Witzgall, P., Kirsch, P. \& Cork, A. Sex pheromones and their impact on pest management. J. Chem. Ecol. 36, 80-100 (2010)

20. Hsu, J. C., Haymer, D. S., Wu, W. J. \& Feng, H. T. Mutations in the acetylcholinesterase gene of Bactrocera dorsalis associated with resistance to organophosphorus insecticides. Insect Biochem. Mol. Biol. 36, 396-402 (2006).

21. Daane, K. M. \& Johnson, M. W. Olive fruit fly: Managing an ancient pest in modern times. Annu. Rev Entomol 55, 151-169 (2010).

22. Vargas, R. I. et al. Attraction and mortality of oriental fruit flies to SPLAT-MATmethyl eugenol with spinosad. Entomol. Exp. Appli. 131, 286-293 (2009).
23. Vargas, R. I. et al. Evaluation of SPLAT with spinosad and methyl eugenol or cuelure for "attract-and-kill" of oriental and melon fruit flies (Diptera: Tephritidae) in Hawaii. J. Econ. Entomol. 101, 759-768 (2008).

24. Leblanc, L., Vargas, R. I., MacKey, B., Putoa, R. \& Pinero, J. C. Evaluation of cuelure and methyl eugenol solid lure and insecticide dispensers for fruit fly (Diptera: Tephritidae) monitoring and control in Tahiti. Florida Entomol. 94, 510-516 (2011).

25. Thomson, D. R., Gut, L. J. \& Jenkins, J. W. Biopesticides: use and delivery, Ed. Hall, F. R. \& Menn, J. J. Humana Press Inc., New Jersey, 385-412 (1999).

26. Campion, D. G., Critchley, B. R. \& McVeigh, L. J. Mating disruption. In Insect Pheromones in Plant Protection; Ed. Jutsum, A. R. \& Gordon, R. F. S. Wiley: New York, 89-119 (1985).

27. Evans, T. A., Dawes, T. Z., Ward, P. R. \& Lo, N. Ants and termites increase crop yield in a dry climate. Nat. Commun. 2, 262-268 (2011).

28. Cork, A. Pheromone manual. Chatham Maritime, UK: Natural Resources Institute, Chapter 4, 13-17 (2004).

29. Heuskin, S., Verheggen, F. J., Haubruge, E., Wathelet, J.-P. \& Lognay, G. The use of semiochemical slow-release devices in integrated pest management strategies. Biotechnol. Agron. Soc. Environ. 15, 459-470 (2011).

30. White, I. M. \& Elson-Harris, M. M. Fruit flies of economic significance: their identification and bionomics. CAB International, Wallingford, UK, 601 (1992).

31. Shelly, T. E. et al. Capture of Bactrocera fruit flies (Diptera: Tephritidae) in traps baited with liquid versus solid formulations of male lures. J. Asia-Pacific Entomol. 14, 463-467 (2011)

32. Jadhav, S. R. et al. Molecular gels-based controlled release devices for pheromones. Soft Matter 7, 864-867 (2011)

33. Bhattacharya, S. \& Samanta, S. K. Soft functional materials induced by fibrillar networks of small molecular photochromic gelators. Langmuir 25, 8378-8381 (2009).

34. Terech, P. \& Weiss, R. G. Low molecular mass gelators of organic liquids and the properties of their gels. Chem. Rev. 97, 3133-3159 (1997).

35. Samanta, S. K., Pal, A. \& Bhattacharya, S. Choice of the end functional groups in tri( $p$-phenylenevinylene) derivatives controls its physical gelation abilities. Langmuir 25, 8567-8578 (2009).

36. Samanta, S. K. \& Bhattacharya, S. Wide range light harvesting donor-acceptor assemblies through inter-gelator interactions via self-assembly. Chem. Eur. J. 18, 15875-15885 (2012)

37. Samanta, S. K., Subrahmanyam, K. S., Bhattacharya, S. \& Rao, C. N. R. Composites of Graphene and other Nanocarbons with Gelators Assembled through Supramolecular Interactions. Chem. Eur. J. 18, 2890-2901 (2012).

38. Bhattacharya, S. \& Samanta, S. K. Unusual salt induced color modulation through aggregation-induced emission switching of bis-cationic phenylenedivinylene based $\pi$-hydrogelator. Chem. Eur. J. 18, 16632-16641 (2012).

39. Samanta, S. K. \& Bhattacharya, S. Aggregation induced emission switching and electrical properties of chain length dependent $\pi$-gels derived from phenylenedivinylene bis-pyridinium salts in alcohol-water mixtures. J. Mater. Chem. 22, 25277-25287 (2012).

40. Ibrahim, A. G., Singh, G. \& King, H. S. Trapping of the Fruit-flies, Dacus spp (Diptera: Tephritidae) with methyl eugenol in Orchards. Pertanika 2, 58-61 (1979).

41. Yamamura, K. Transformation using $(\mathrm{x}+0.5)$ to stabilize the variance of populations. Res. Popul. Ecol. 41, 229-234 (1999).

42. Gomez, K. A. \& Gomez, A. A. Statistical procedures for Agricultural research. Second edition, pp. 17 (1984)

\section{Acknowledgements}

DB thanks the present and past Directors of NBAII, Bangalore for their encouragements. We thank DST, Government of India (J C Bose Fellowship to SB), INI, IISc for the SEM and TEM studies, DBT, Government of India for funding this work. We thank Dr. K. J. David for the identification of Bactrocera dorsalis (Hendel).

\section{Author contributions}

S.B. conceived the idea, designed experiments and analyzed results. S.B. also mentored the entire work and provided the necessary facilities to execute the work. D.B. and S.K.S. have contributed equally to this work. D.B. has performed the field trials, made the data analyses and other laboratory experiments. S.K.S. has prepared the nanogel and studied the physical properties. All contributed to the discussion of the results and writing of the manuscript.

\section{Additional information}

Supplementary information accompanies this paper at http://www.nature.com/ scientificreports

Competing financial interests: The authors declare no competing financial interests.

License: This work is licensed under a Creative Commons

Attribution-NonCommercial-NoDerivs 3.0 Unported License. To view a copy of this license, visit http://creativecommons.org/licenses/by-nc-nd/3.0/

How to cite this article: Bhagat, D., Samanta, S.K. \& Bhattacharya, S. Efficient Management of Fruit Pests by Pheromone Nanogels. Sci. Rep. 3, 1294; DOI:10.1038/srep01294 (2013). 